\title{
Assessment of serum vitamin D level in patients with systemic lupus erythematosus
}

Fahmi E. Emam ${ }^{b}$, Taghreed M. Abd El-Wahab ${ }^{b}$, Maha S. Mohammed ${ }^{b}$, Amal S. Elsalhy ${ }^{b}$, Sabah I. Abdel Rahem ${ }^{a}$

aDepartment of Physical Medicine, Rheumatology and Rehabilitation and Department of Clinical Pathology, ${ }^{b}$ Faculty of Medicine for girls, Al Azhar University, Cairo, Egypt

Correspondence to Taghreed Mohamed Abd El-Wahab, 15, Ahmed Mohamed Ibraheim St. Abbas Elakad, Nasr City, $12^{\text {th }}$ Storey, Flat no. 23 Tel: 0020223717931;

e-mail: dr_almohandis@yahoo.com

Received 1 November 2013

Accepted 15 January 2014

Egyptian Rheumatology \& Rehabilitation 2014, 41:71-78

\begin{abstract}
Objective
To evaluate the serum level of vitamin D in patients with systemic lupus erythematosus (SLE) and its relationship with disease activity.

Patients and methods

Forty patients suffering from SLE were enrolled in this study (group I). They were further divided into two subgroups according to the SLE disease activity index (SLEDAI) score: group la with respect to disease activity and group $\mathrm{lb}$ with respect to disease remission. Another 20 agematched and sex-matched healthy individuals were chosen as control group II. All patients underwent complete medical history taking and thorough clinical examination; the disease activity was assessed by the use of SLEDAI score. Serum vitamin D level in all patients and controls was measured.

Results

Vitamin D level was significantly higher in controls than in patients. The vitamin D deficiency was highly prevalent among patients with disease activity than in the remission group. There was highly significant inverse correlation between vitamin D level and SLEDAI score in the patient group. Vitamin $D$ level correlated inversely with $C$ reactive protein $(C R P)$ and anti-dsDNA in the disease activity group, whereas it correlated positively with C3.

Conclusion

Vitamin D deficiency is prevalent in SLE patients more than in healthy controls; vitamin D deficiency is highly prevalent among patients with disease activity than in the remission group, and vitamin $\mathrm{D}$ level correlated inversely with disease activity, which suggest that inadequate vitamin D level, among other factors, probably contributed to the development of active disease in patients with SLE.
\end{abstract}

\section{Keywords:}

disease activity (SLEDAI); systemic lupus erythematosus, vitamin D level

Egypt Rheumatol Rehabil 41:71-78

(C) 2014 Egyptian Society for Rheumatology and Rehabilitation

$1110-161 X$

\section{Introduction}

Systemic lupus erythematosus (SLE) is an autoimmune disorder characterized by multisystem microvascular inflammation with the generation of autoantibodies. Although the specific cause of SLE is unknown, multiple factors are associated with the development of the disease, including genetic, racial, hormonal, and environmental factors [1].

Many clinical manifestations of SLE are mediated by circulating immune complexes in various tissues or by the direct effects of antibodies to cell surface components. Immune complexes form in the microvasculature, leading to complement activation and inflammation. Moreover, antibody-antigen complexes deposit on the basement membranes of the skin and kidneys [2]. In active SLE, this process has been confirmed by demonstration of complexes of nuclear antigens such as DNA, immunoglobulins, and complement proteins at these sites. Autoantibodies have been found to be the biomarkers for future neuropsychiatric events in SLE [3].
Vitamin D is an essential steroid hormone with wellestablished effects on mineral metabolism and skeletal health, and with more recently described effects on cardiovascular and immune health [4].

The importance of vitamin $\mathrm{D}$ in immune regulation has gained increased interest over the past decade, with the discovery of the vitamin $\mathrm{D}$ receptor being expressed by the cells of the immune system and manipulation of 1,25-dihydroxyvitamin $\mathrm{D}$ [1,25(OH)2D] having downstream immune effects. The overall immunologic effects of $1,25(\mathrm{OH}) 2 \mathrm{D}$ include downregulating Th1 immune responses, modulating the differentiation of dendritic cells, and lowering proliferation of activated $\mathrm{B}$ cells, whereas upregulating regulatory $\mathrm{T}$ cells and preserving innate immune responses. Each of the immune pathways influenced by $1,25(\mathrm{OH}) 2 \mathrm{D}$ has profound potential implications for patients with SLE [5].

Patients with SLE have multiple risk factors for vitamin $\mathrm{D}$ deficiency. The photosensitivity characteristic of SLE determines a lower sun exposure and the use 
of sunscreen, which blocks UVB radiation, reducing the skin production of vitamin D. Chronic use of corticosteroids, drugs of frequent use in the treatment of patients with SLE, changes the vitamin D metabolism. In addition, severe renal impairment, which can occur in patients with lupus nephritis, can change the stage of hydroxylation of vitamin D [6].

The purpose of this study was to evaluate the serum level of vitamin D in patients with SLE and its relationship with disease activity.

\section{Patients and method}

This study was performed on 40 SLE patients attending the outpatient clinic of Physical Medicine Rheumatology and Rehabilitation Department at Al Zahraa, Al Sayed Galal, and Al Hussein University Hospitals.

The patients were diagnosed according to the 1982 revised criteria of The American College of Rheumatology for the diagnosis of SLE [7]. We classified the patients as group I, in addition to 20 age-matched and sex-matched controls classified as group II. Written informed consent was obtained from all patients and controls for their study participation. The study was approved by the local ethics committee of faculty of medicine for girls.

\section{Exclusion criteria}

Patients with other connective tissue diseases, patients with chronic debilitating diseases, and pregnant and lactating patients were excluded from the study.

\section{Clinical examination}

Patients were subjected to complete history taking and complete clinical examination, including general, locomotor system, skin, cardiovascular, chest, neurological, and vascular examinations.

\section{Disease activity}

The disease activity was assessed in SLE patients by the Systemic Lupus Erythematosus Disease Activity Index (SLEDAI) [8]. Patients with SLEDAI score of more than 6 are considered in a state of active disease (group Ia) and patients with SLEDAI score of less than 6 are considered in a state of inactive disease (remission) (group Ib).

\section{Laboratory assessment}

(1) Complete blood profile (assayed by automated counter Sysmex KX-21 N, USA-Mundelein).
(2) CRP using AVITEX CRP (rapid latex agglutination test kit, B00BA-Omega diagnostics, Burlington/ontario).

(3) Erythrocyte sedimentation rate (ESR) using the Westergren method.

(4) Complete urine analysis and total protein (g) in 24-h urine collection.

(5) ANA by ELISA technique.

(6) Anti-dsDNA autoantibody by ELISA technique using Calbiotich kits (CAT NO DDO37G lifescience company USA-CA).

(7) Serum complement (C3) by single radial immunodiffusion method using Astra Formedic C3 Monorid plates (Astra diagnostic, Milano).

(8) Measurement of serum vitamin D level by the immunodiagnostic enzyme immunoassay kits (REF K 2110 Arbeitsanleitung company Australien). Principle of the test according to Wielders and Wijnberg [9].

This test kit is a competitive protein-binding assay for the measurement of $25-\mathrm{OH}$ vitamin $\mathrm{D}$. It is based on the competition of $25-\mathrm{OH}$ vitamin $\mathrm{D}$ present in the sample with $25-\mathrm{OH}$ vitamin $\mathrm{D}$ tracer for the binding pocket of vitamin D-binding protein (VDBP, Gc-globulin). As all circulating $25-\mathrm{OH}$ vitamin $\mathrm{D}$ is bound to VDBP in vivo, samples have to be precipitated with precipitation reagent to extract the analyte. The supernatant can be used without further treatment within the test. In the first incubation step, sample, calibrator, control, VDBP, and the VDBP antibody, an antibody specific for this protein, are added to the solid phase. $25-\mathrm{OH}$ vitamin $\mathrm{D}$ present in the sample then competes with the tracer, coated on the well, for the specific binding site of the binding protein, and the VDBP antibody is bound to the vitamin-binding protein. After a washing step to remove unbound components, the quantitation of VDBP is achieved by incubation with a host-specific peroxidase-labeled antibody using tetramethylbenzidine as enzyme substrate. An acidic stopping solution is then added to stop the reaction. The color converts to yellow. The intensity of the yellow color is indirectly proportional to the concentration of $25-\mathrm{OH}$ vitamin $\mathrm{D}$ in the sample. A dose-response curve of the absorbance unit versus concentration is generated using the results obtained from the calibrators. Concentrations of $25-\mathrm{OH}$ vitamin $\mathrm{D}$, present in the patient samples, are determined directly from this curve.

Information from the American Society for Bone and Mineral Research (ASBMR 2006) on 25-OH vitamin $\mathrm{D}$ are as follows:

(1) Deficiency (seriously deficient): less than $12 \mathrm{ng} / \mathrm{ml}$, respectively, less than $30 \mathrm{nmol} / 1$. 
(2) Insufficiency (deficient): $12-30 \mathrm{ng} / \mathrm{ml}$, respectively, less than $30-75 \mathrm{nmol} / 1$.

(3) Sufficiency (adequately supplied): more than $30 \mathrm{ng} / \mathrm{ml}$, respectively, more than $75 \mathrm{nmol} / 1$.

(4) $1 \mathrm{ng} / \mathrm{ml}=2.5 \mathrm{nmol} / 1$

(5) $1 \mathrm{nmol} / 1=0.4 \mathrm{ng} / \mathrm{ml}$

The statistical analysis was carried out using statistical package for social science (version 16). Quantitative variables were described by mean $\pm \mathrm{SD}$ and range (maximum-minimum).

Qualitative categorical variables were described by proportions and percentages.

Data were analyzed using the independent samples $t$-tests for comparing two groups and one-way analysis of variance (ANOVA) in case of three groups followed by the Scheffe multiple comparison procedure.

Determination of the extent that a single observed series of proportions differs from a theoretical or expected distribution was performed by the $\chi^{2}$-test.

Pearson correlation coefficient was used to measure correlation.

$P$ value greater than 0.05 was considered nonsignificant, $P$ value less than 0.05 was considered significant, and $P$ value less than 0.01 was considered highly significant.

\section{Results}

\section{Demographic data of the patient and control groups}

This study was performed on 40 SLE patients (group I), 38 female patients (95\%) and two male patients (5\%). Their ages ranged between 16 and 45 years with a mean of $29.75 \pm 6.93$ years, and the disease duration ranged from 0.8 to 19 years with a mean of $5.23 \pm 4.21$ years. They were diagnosed according to the 1982 revised criteria of The American College of Rheumatology for the diagnosis of SLE [7]. In addition, 20 age-matched healthy controls (group II) were included, 18 female patients (90\%) and two male patients (10\%). Group I was classified according to the systemic SLEDAI into two subgroups: group Ia included 20 patients with disease activity (SLEDAI>6), 18 (90\%) female patients and two (10\%) male patients with mean age of $27.90 \pm 5.88$ years, and group Ib included 20 patients with remission (SLEDAI $£ 6$ ), all female patients with mean age of $29.90 \pm 6.85$ years.

\section{Clinical manifestations of SLE}

The most frequent clinical manifestations among patients of group I were photosensitivity 52.5\% (21 patients) and mucocutaneous manifestations [rash 57\% (23 patients), mucosal ulcers 45\% (18 patients), and alopecia 42.5\% (17 patients)]. Cardiac, renal, and pulmonary involvements were 30\% (12 patients), $27.5 \%$ (11 patients), and 25\% (10 patients), respectively. Musculoskeletal manifestations were: arthritis 28\% (11 patients) and myositis 15\% (six patients). Fever was found in 23\% (nine patients) and CNS involvement was limited in our sample [headache 13\%, (five patients), seizures $13 \%$ (five patients), and cranial nerves involvement 5\% (two patients)] (Fig. 1).

\section{Laboratory investigations among SLE patients}

Comparison between group Ia and Ib with respect to laboratory data showed that group Ia patients had significantly higher level of total proteins in $24 \mathrm{~h}$ and anti-dsDNA, whereas they had significantly lower C3 level than group Ib patients $(P<0.01)$. However, there was no statistical significant difference between group Ia and group Ib patients with respect to ESR and CRP $(P>0.05)$ (Table 1).

\section{Disease activity of SLE patients}

On comparing group Ia and group Ib with respect to SLEDAI score, it was revealed that there was high statistically significant difference between the two groups with respect to SLEDAI score $(P=0.000)$ (Table 2$)$.

\section{Serum levels of vitamin D in the SLE and control groups}

Comparison between group I and group II with respect to vitamin $\mathrm{D}$ level revealed that vitamin $\mathrm{D}$ level ranged from 1.9 to $47 \mathrm{ng} / \mathrm{ml}$ in group I (with mean of

\section{Figure 1}

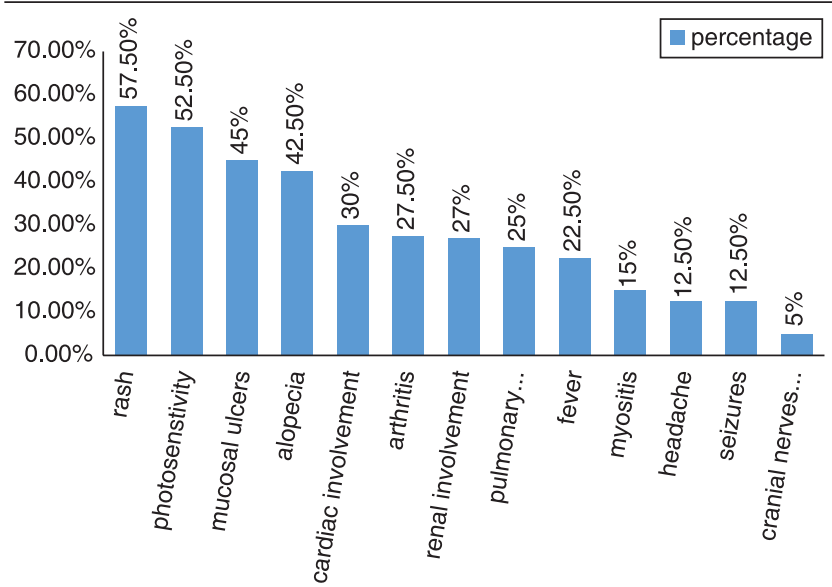

The frequencies of clinical data in group I. 
$13.84 \pm 12.16 \mathrm{ng} / \mathrm{ml}$ ), whereas in group II it ranged from 9 to $42 \mathrm{ng} / \mathrm{ml}$, with mean of $22.37 \pm 11.73 \mathrm{ng} / \mathrm{ml}$. There was high statistically significant difference between the two groups $(P=0.0091)$ with higher mean in group II (Table 3).

Vitamin D status in group I and group II: in group I, 27 patients $(67.5 \%)$ had vitamin $\mathrm{D}$ deficiency ( $<12 \mathrm{ng} / \mathrm{ml}$ ), seven patients $(17.5 \%)$ had vitamin D insufficiency $(12-30 \mathrm{ng} / \mathrm{ml})$, and six patients $(15 \%)$ had vitamin D sufficiency $(>30 \mathrm{ng} / \mathrm{ml})$, whereas in group II six patients (30\%) had vitamin D deficiency, six patients (30\%) had vitamin D insufficiency, and eight patients (40\%) had vitamin D sufficiency. There was statistically significant difference in vitamin $\mathrm{D}$ levels of group I and group II $(P=0.019)$.(Table 4).

\section{Association between serum vitamin $D$ levels} and clinical presentations in SLE patients

There was significantly lower vitamin D level among patients with photosensitivity, rash, arthritis, and renal involvement in group I and it was highly significantly lower in patients with cardiac involvement, whereas there was no significant difference between vitamin $\mathrm{D}$ levels in patients with and without fever, alopecia, mucosal ulcers, myositis, headache, seizures, and pulmonary involvement.

\section{vitamin $D$ levels among SLEDAI subgroups}

On comparing group $\mathrm{Ia}, \mathrm{Ib}$, and group II with respect to vitamin $D$ level, there was high statistically significant difference between the three groups $(P=0.000015)$ (Table 5).

Table 1 Showing comparison between group la and lb with respect to laboratory data

\begin{tabular}{|c|c|c|c|c|c|c|c|}
\hline \multirow[t]{2}{*}{ Laboratory data } & \multicolumn{2}{|c|}{ Group la $(n=20)$} & \multicolumn{2}{|c|}{ Group Ib $(n=20)$} & \multirow[t]{2}{*}{$T$} & \multirow[t]{2}{*}{$P$-value } & \multirow[t]{2}{*}{ Significance } \\
\hline & Range & Mean \pm SD & Range & Mean \pm SD & & & \\
\hline $\begin{array}{l}\text { Total proteinuria in } \\
24 \mathrm{~h}\end{array}$ & $0.10-6$ & $1.03 \pm 1.40$ & $0.1-0.32$ & $0.17 \pm 0.06$ & 2.729 & 0.0096 & $\mathrm{HS}$ \\
\hline ESR & $15-130$ & $53.80 \pm 32.78$ & $17-100$ & $37.50 \pm 23.41$ & 1.810 & 0.0783 & NS \\
\hline CRP & $0-48$ & $8.15 \pm 14.02$ & $1-24$ & $6.60 \pm 5.48$ & 0.461 & 0.6477 & NS \\
\hline C3 & $45-138$ & $87.39 \pm 27.23$ & $97-156$ & $118.55 \pm 19.78$ & -4.140 & 0.0002 & HS \\
\hline Anti-dsDNA & $0.4-10$ & $4.00 \pm 2.91$ & $0.2-3$ & $1.40 \pm 0.92$ & 3.807 & 0.0005 & HS \\
\hline
\end{tabular}

CRP, C-reactive protein; ESR, erythrocyte sedimentation rate; HS, highly significant.

Table 2 Showing comparison between group la and Ib with respect to systemic lupus erythematosus disease activity index score

\begin{tabular}{|c|c|c|c|c|c|c|c|}
\hline \multirow{2}{*}{$\begin{array}{l}\text { Systemic lupus erythematosus } \\
\text { disease activity index }\end{array}$} & \multicolumn{2}{|c|}{ Group Ia $(n=20)$} & \multicolumn{2}{|c|}{ Group Ib $(n=20)$} & \multirow[t]{2}{*}{$T$} & \multirow[t]{2}{*}{$P$} & \multirow[t]{2}{*}{ Significance } \\
\hline & Range & Mean \pm SD & Range & Mean \pm SD & & & \\
\hline LEDAI score & $7-32$ & $16.90 \pm 7.41$ & $0-6$ & $2.85 \pm 1.98$ & 8.190 & 0.000 & $\mathrm{HS}$ \\
\hline
\end{tabular}

HS, highly significant; SLEDAI, systemic lupus erythematosus disease activity index.

Table 3 Showing comparison between group I and group II with respect to vitamin D level

\begin{tabular}{|c|c|c|c|c|c|c|c|}
\hline \multirow[t]{2}{*}{ Vitamin D level } & \multicolumn{2}{|c|}{ Group I $(n=40)$} & \multicolumn{2}{|c|}{ Group II $(n=20)$} & \multirow[t]{2}{*}{$T$} & \multirow[t]{2}{*}{$P$} & \multirow[t]{2}{*}{ Significance } \\
\hline & Range & Mean \pm SD & Range & Mean \pm SD & & & \\
\hline Vitamin D & $1.9-47$ & $13.84 \pm 12.16$ & $9-42$ & $22.73 \pm 11.73$ & -2.699 & 0.0091 & $\mathrm{HS}$ \\
\hline
\end{tabular}

HS, highly significant.

Table 4 Showing comparison between group I and group II in different vitamin D levels

\begin{tabular}{|c|c|c|c|c|c|c|}
\hline \multirow[t]{2}{*}{ Different vitamin D levels } & \multicolumn{2}{|c|}{$n(\%)$} & \multirow[t]{2}{*}{ Total } & \multirow[t]{2}{*}{$\chi^{2}$} & \multirow[t]{2}{*}{$P$} & \multirow[t]{2}{*}{ Significance } \\
\hline & Group I $(n=40)$ & Group II $(n=20)$ & & & & \\
\hline Deficiency $<12 \mathrm{ng} / \mathrm{ml}$ & $27(67.5)$ & $6(30.0)$ & 33 & 7.94 & 0.019 & $S$ \\
\hline Insufficiency $12-30 \mathrm{ng} / \mathrm{ml}$ & 7 (17.5) & $6(30.0)$ & 13 & & & \\
\hline Sufficiency $>30 \mathrm{ng} / \mathrm{ml}$ & $6(15.0)$ & $8(40.0)$ & 14 & & & \\
\hline Total & 40 & 20 & 60 & & & \\
\hline
\end{tabular}

Table 5 Showing ANOVA comparison between group la, group lb, and group II with respect to vitamin D level

\begin{tabular}{|c|c|c|c|c|c|c|}
\hline \multirow[t]{2}{*}{ Groups } & \multicolumn{6}{|c|}{ ANOVA } \\
\hline & $N$ & Range & Mean \pm SD & $F$ & $P$ & Significance \\
\hline Group la & 20 & $1.90-11.30$ & $6.79 \pm 3.02$ & 13.5 & 0.000015 & HS \\
\hline Group Ib & 20 & $2.70-47.00$ & $20.89 \pm 13.78$ & & & \\
\hline Group II & 20 & $9.00-42.00$ & $22.73 \pm 11.73$ & & & \\
\hline
\end{tabular}

ANOVA, analysis of variance. 
On comparing mean vitamin $\mathrm{D}$ level in group Ia and $\mathrm{Ib}$ and in group Ia and II, the difference was highly significant, whereas there was no significant difference on comparing mean vitamin $\mathrm{D}$ level in group $\mathrm{Ib}$ and II (Table 6).

\section{Correlation between serum vitamin $D$ levels and SLEDAI score, anti-dsDNA, complement C3, age,} disease duration, $24 \mathrm{~h}$ total proteinuria, ESR, and CRP Correlative study in group I and subgroup group Ia and group $\mathrm{Ib}$ with respect to vitamin D level with SLEDAI score, anti-dsDNA, complement $\mathrm{C} 3$, age, disease duration, $24 \mathrm{~h}$ total proteinuria, ESR, and CRP showed that, in group I there was highly significant inverse correlation between vitamin D level and SLEDAI score $(r=-0.59, P=0.000)$; there was significant inverse correlation between vitamin D level and anti-dsDNA $(r=-0.39, P=0.012)$; and there was significant positive correlation between vitamin $\mathrm{D}$ level and complement $\mathrm{C} 3$ $(r=0.40, P=0.011)$. However, there was nonsignificant correlation between vitamin D level and age $(r=0.01, P$ $=0.947)$, vitamin $\mathrm{D}$ level and disease duration $(r=0.04$, $P=0.805)$, vitamin D level and $24 \mathrm{~h}$ total proteinuria $(r$ $=-0.26, P=0.111)$, vitamin D level and ESR $(r=-0.04$, $P=0.784)$, and vitamin D level and CRP $(r=-0.19, P$ $=0.244)$ (Figs 2-4).

In group Ia, there was significant inverse correlation between vitamin D level and SLEDAI score $(r=-0.54$,

Table 6 Showing multiple comparisons by the Scheffe method

\begin{tabular}{lcc}
\hline & $P$-value & Significance \\
\hline Group la and group Ib & 0.000175 & HS \\
Group la and group II & 0.000024 & HS \\
Group Ib and group II & 0.844854 & NS \\
\hline
\end{tabular}

HS, highly significant.

Figure 2

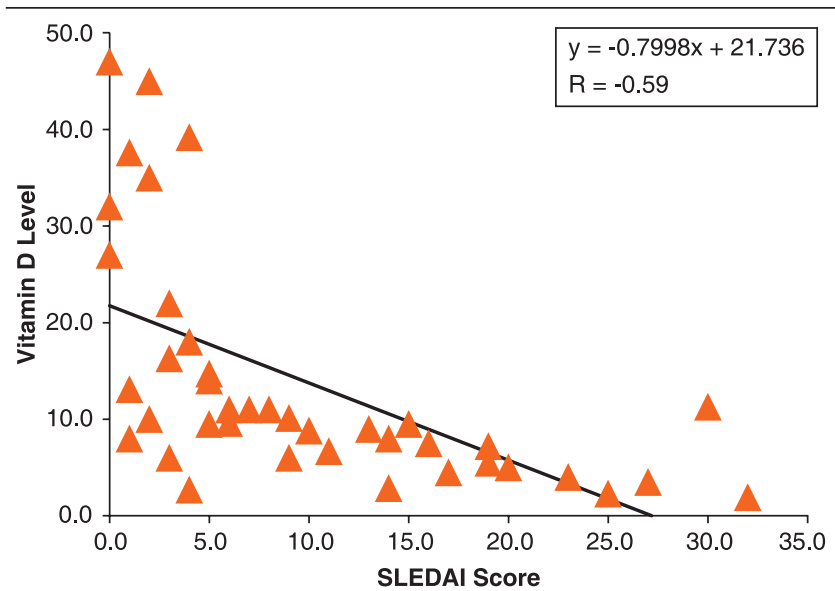

Highly significant inverse correlation between vitamin D level and systemic lupus erythematosus disease activity index (SLEDAI) score in group I.
$P=0.015)$, vitamin D level and anti-dsDNA $(r=-0.64$, $P=0.04)$, and vitamin D level and CRP $(r=-0.55$, $P=0.013)$. There was significant positive correlation between vitamin $\mathrm{D}$ level and complement C3 $(r=0.45, P=0.045)$, whereas there was nonsignificant correlation between vitamin D level and age $(r=0.12$, $P=0.627)$, vitamin $\mathrm{D}$ level and disease duration $(r=0.06, P=0.791)$, vitamin $\mathrm{D}$ level and $24 \mathrm{~h}$ total proteinurea $(r=-0.10, P=0.685)$, and vitamin $\mathrm{D}$ level and $\operatorname{ESR}(r=0.000, P=0.994)$ (Figs $5-8)$.

In group Ib, there was a significant inverse correlation between vitamin D level and SLEDAI score only, whereas there was nonsignificant correlation between vitamin $\mathrm{D}$ level and age $(r=-0.16, P=0.499)$, vitamin $\mathrm{D}$ level and disease duration $(r=-0.15, P=0.542)$, vitamin D level and $24 \mathrm{~h}$ total proteinurea $(r=-0.09$, $P=0.708)$, vitamin D level and ESR $(r=0.27, P=0.242)$, vitamin D level and CRP $(r=-0.20, P=0.404)$, vitamin $\mathrm{D}$ level and complement C3 ( $r=0.04, P=0.853)$, and vitamin D level and anti-dsDNA $(r=-0.09, P=0.709)$ (Fig. 9).

\section{Discussion}

Although the factors contributing to the pathogenesis of SLE have not yet been completely clarified, genetic mechanisms, and environmental, hormonal, and immune factors are known to be implicated [10]. Among the environmental factors, vitamin $\mathrm{D}$ has been the subject of an increasing number of studies in recent years, which have demonstrated its role in autoimmunity [11].

The wide distribution and expression of the vitamin $\mathrm{D}$ receptor in most immune cells, such as monocytes, macrophages, dendritic cells, natural

Figure 3

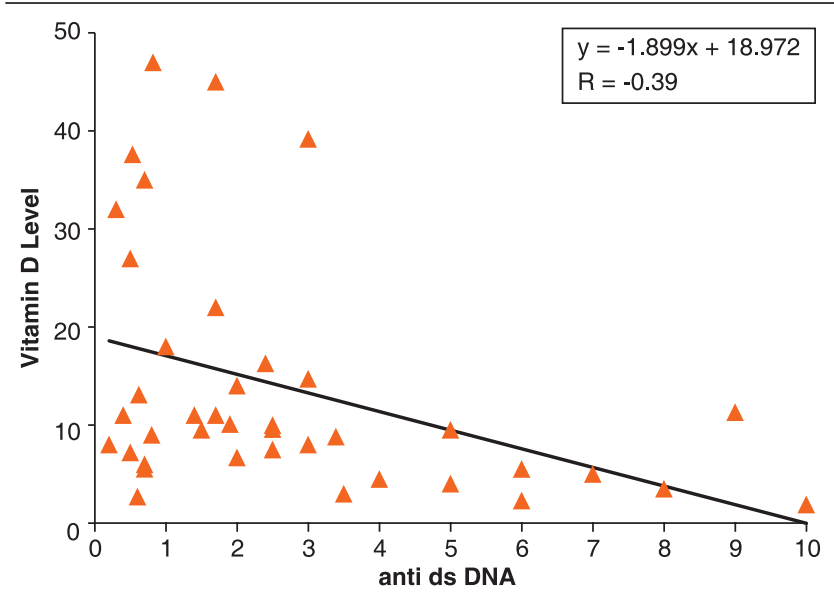

Significant inverse correlation between vitamin $D$ level and antidsDNA in group I. 


\section{Figure 4}

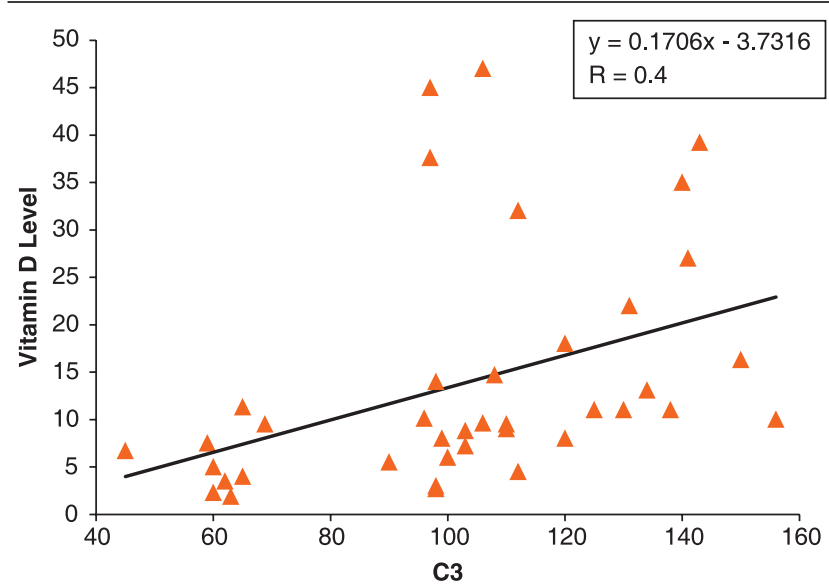

Significant positive correlation between vitamin $\mathrm{D}$ level and complement $\mathrm{C} 3$ in group I.

Figure 6

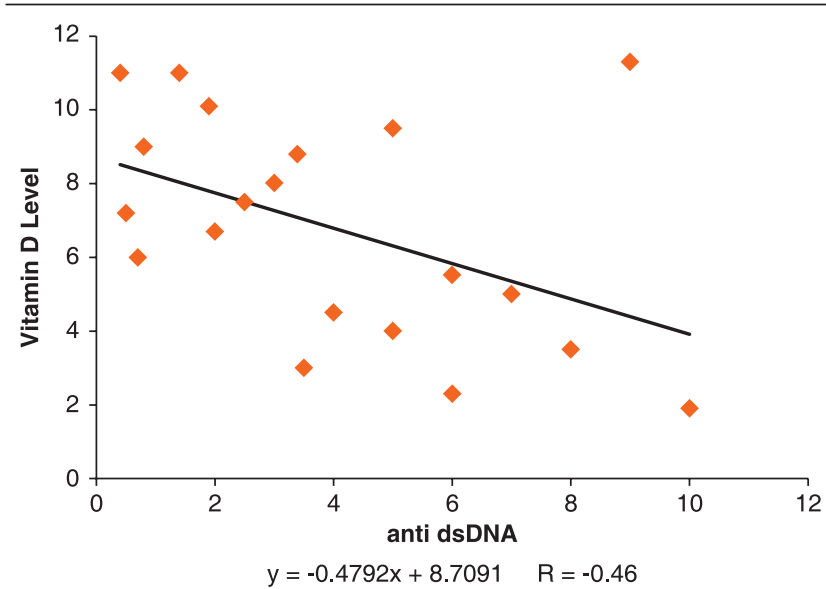

Significant inverse correlation between vitamin $D$ level and anti-dsDNA in group la.

\section{Figure 8}

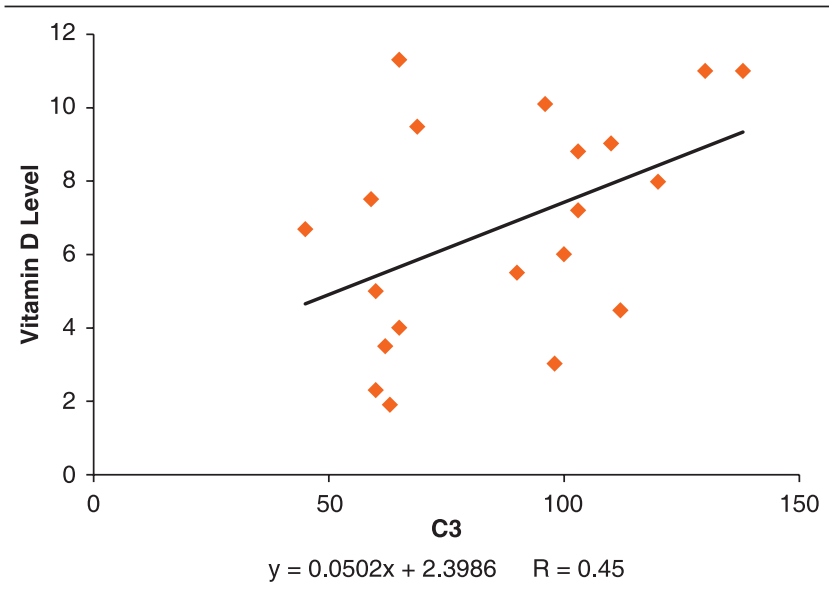

Significant positive correlation between vitamin $D$ level and complement C3 in group la.

killer cells, and $\mathrm{T}$ and $\mathrm{B}$ lymphocytes, in addition to its effect on cell proliferation and differentiation,
Figure 5

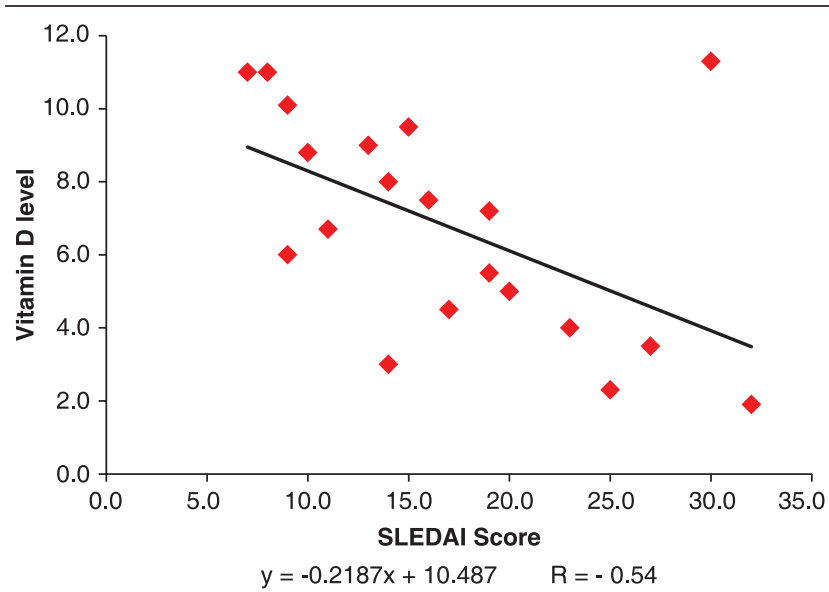

Significant inverse correlation between vitamin $D$ level and systemic lupus erythematosus disease activity index (SLEDAI) score in group la.

\section{Figure 7}

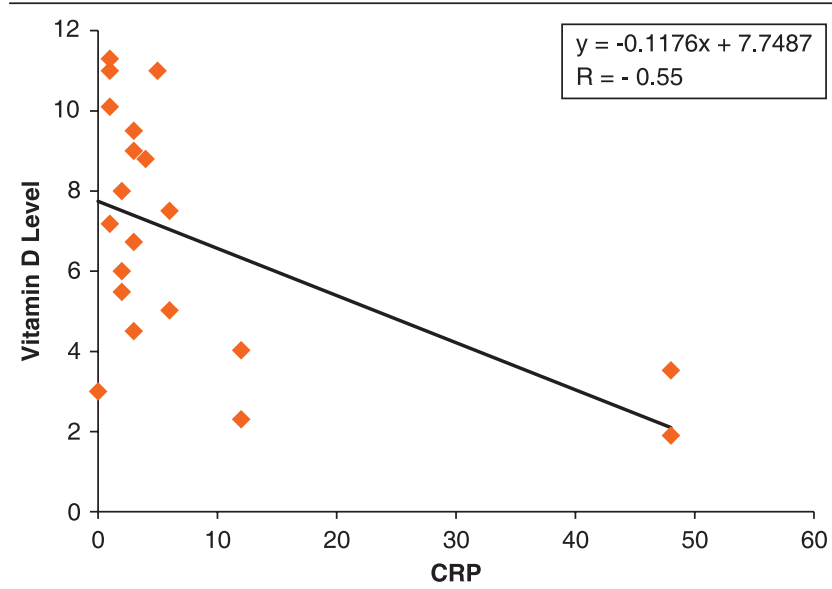

Significant inverse correlation between vitamin $\mathrm{D}$ level and C-reactive protein (CRP) in group la.

Figure 9

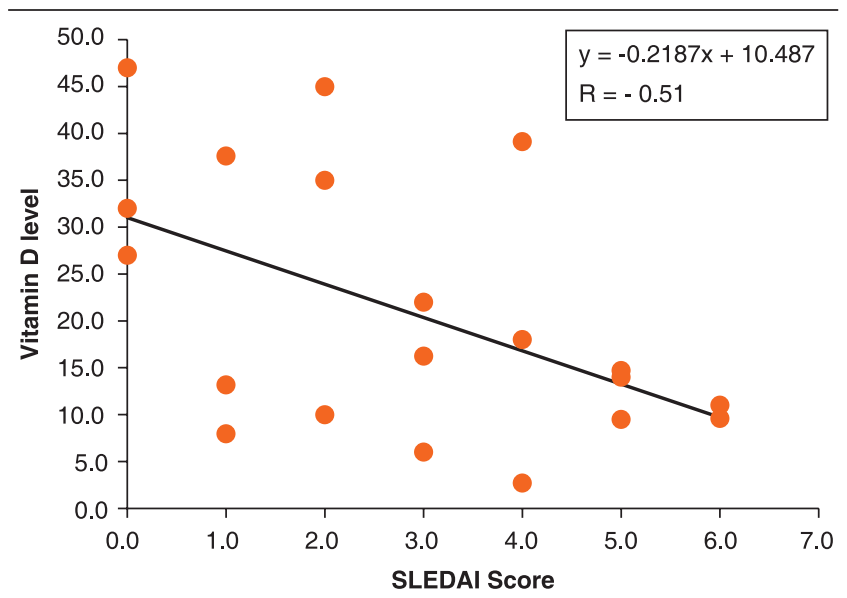

Significant inverse correlation between vitamin D level and systemic lupus erythematosus disease activity index (SLEDAI) score in group lb.

makes vitamin $\mathrm{D}$ a potential candidate for immune system regulation [12]. 
Because patients with SLE are advised to avoid direct sunlight, a common trigger of disease flares but also the primary source of vitamin D3, the risk for vitamin $\mathrm{D}$ deficiency is even higher among SLE patients than in the general population [13].

This study revealed low vitamin D level in patients with SLE compared with healthy controls. We found also that $85 \%$ of our patients had inadequate (insufficient and deficient) vitamin $\mathrm{D}$ level ( $<30 \mathrm{ng} / \mathrm{ml})$, whereas $15 \%$ only had sufficient vitamin D level $(>30 \mathrm{ng} / \mathrm{ml})$. However, in the control group $60 \%$ had inadequate vitamin D level and only $40 \%$ had sufficient level. This means that vitamin $\mathrm{D}$ deficiency is prevalent in SLE patients more than in healthy controls, although the later group shows relatively high prevalence of deficiency and insufficiency; this was explained by Fragoso et al. [10] to be a result from modern life activities, which make us avoid sun exposure, and consequently reduce vitamin $\mathrm{D}$ synthesis.

Our findings are in agreement with those of Damanhouri [14] who conducted a study on 165 SLE patients and 214 healthy controls and found that the prevalence of SLE patients with $25(\mathrm{OH}) \mathrm{D}$ inadequacy and deficiency was higher than in the control group: 98.8 versus $55 \%, 89.7$ versus $20 \%(P<0.0001)$. Only two (1.2\%) SLE patients had adequate levels of $25(\mathrm{OH}) \mathrm{D}$ compared with 96 (45\%) individuals of the control group $(P<0.0001)$. Another study conducted by Handono et al. [15] also found that $20.37 \%$ of 54 female patients with SLE had normal vitamin D serum level, $24.7 \%$ had insufficiency, and $55.56 \%$ had deficiency of vitamin D. In addition, Kamen et al. [16] found lower $25(\mathrm{OH}) \mathrm{D}$ in $123 \mathrm{SLE}$ patients when compared with 240 age-matched and sex-matched population controls. In addition, Thudi et al. [17] found that $65 \%$ of 25 SLE patients were vitamin D deficient. In contrast,Stockton et al. [18] who conducted their study on 24 SLE female patients and 21 healthy female controls found that there was no significant difference in $25(\mathrm{OH}) \mathrm{D}$ levels between groups, and mean $25(\mathrm{OH}) \mathrm{D}$ levels of the SLE group was $73.9 \mathrm{nmol} / 1$ $(29.6 \mathrm{ng} / \mathrm{ml})$. The authors explained that this difference was because this study was conducted in Brisbane, Queensland where ultraviolet radiation levels are high almost all year round; thus, the higher $25(\mathrm{OH}) \mathrm{D}$ levels may reflect inadequate photoprotection. It may be also because the mean SLEDAI score of the patients was 4.3 , which means that they were in mild activity.

We found that there was lower mean vitamin D level in patients with clinical manifestations compared with patients with no clinical manifestations with respect to photosensitivity, rash, arthritis, and renal involvement with a significant difference, whereas it was highly significant with cardiac involvement. Our findings are in agreement with the study by Ruiz-Irastorza et al. [6] who found that photosensitivity and photoprotection predicted vitamin D insufficiency and deficiency, respectively. They concluded that, being populations in whom photosensitivity and the use of photoprotection are frequent, patients with SLE are at a clear risk of developing $25(\mathrm{OH}) \mathrm{D}$ deficiency.

When we classified our patients according to the SLEDAI score into disease activity and remission groups, we found that vitamin D deficiency is highly prevalent among patients with disease activity than in the remission group. All patients with disease activity were vitamin $\mathrm{D}$ deficient, whereas $35 \%$ of the patients in the remission group had vitamin D deficiency, 35\% had insufficiency, and 30\% had normal levels. Our result is in agreement with that of Borba et al. [19] who performed a cross-sectional analysis on 36 SLE patients classified according to the SLEDAI score into high activity (group I: 12 patients, mean age 29.6 years) and minimal activity (group II: 24 patients, mean age 30.0 years), and compared them with normal controls (group III: 26 women, 32.8 years). They found that $25(\mathrm{OH}) \mathrm{D}$ was significantly different among groups $(P<0.001)$; group I presented the lowest levels $(17.4 \pm 12.5)$ compared with groups II and III with mean levels of $44.6 \pm 14.5$ and $37.8 \pm 13.7$, respectively. Handono et al. [15] also conducted their study on 54 female SLE patients in active disease state (SLEDAI score>5) and 23 healthy female controls, and they had found a significant difference between the level of vitamin $D$ in SLE patients and healthy controls $(P=0.000)$.

In addition, we found an inverse correlation between vitamin $\mathrm{D}$ level and disease activity. This relationship was detected in both active disease group (SLEDAI $>6$ ) and the remission group (SLEDAI£6). It was significant in both groups, but it was more stronger in the active disease group $(r=-0.54, P=0.015)$ than $(r=-0.51, P=0.021)$ in the remission group. In the disease activity group, there was an inverse correlation with vitamin D level, anti-dsDNA, and CRP, whereas there was a significant positive correlation with vitamin D level and C3. We did not find significant correlations between vitamin $\mathrm{D}$ level and age, disease duration, ESR, and $24 \mathrm{~h}$ proteinuria in both groups. Our results are in agreement with those of Amital et al. [20] who conducted their study on 378 SLE patients: 278 of them had SLE disease activity-2000 (SLEDAI-2K) scores and 100 patients had European Consensus Lupus Activity Measurement scores. They demonstrated a significant inverse relationship between the degree of SLE activity and serum vitamin D concentration. Although the relationship was weak, it was statistically significant, implying that vitamin $\mathrm{D}$ 
insufficiency, among other factors, probably contributes to the development of active disease in patients with SLE. However, they did not find correlations between vitamin $\mathrm{D}$ level and age and disease duration. Another study by Ruiz-Irastorza et al. [6] did not find relationship between vitamin D level and disease duration. Mok et al. [21] in their study on 290 SLE patients found that 25(OH)D3 level correlated inversely and significantly with clinical SLE activity and anti-dsDNA titers. Ben-Zvi et al. [22] found that vitamin $\mathrm{D}$ level correlated inversely with disease activity measured by the SLEDAI score $(r=-0.234$, $P=0.002)$ in 198 SLE patients.

We concluded that vitamin $\mathrm{D}$ deficiency is prevalent in SLE patients more than in healthy controls; vitamin $\mathrm{D}$ deficiency is highly prevalent among patients with disease activity than in the remission group; and vitamin D level correlated inversely with disease activity, which suggest that inadequate vitamin D level, among other factors, probably contributes to the development of active disease in patients with SLE.

\section{Acknowledgements \\ Conflicts of interest}

There are no conflicts of interest.

\section{References}

1 Rahman A, Isenberg DA. Review article: systemic lupus erythematosus. N Engl J Med 2008; 358:929-939.

2 Hanly JG, Urowitz MB, Su L, et al. Autoantibodies as biomarkers for the prediction of neuropsychiatric events in systemic lupus erythematosus. Ann Rheum Dis 2011; 70:1726-1732.

3 Bosch X. Systemic lupus erythematosus and the neutrophil. N Engl J Med 2011; 365:758-760.

4 Zhao G, Ford ES, Li C, Croft JB, et al. Serum 25-hydroxyvitamin D levels and all-cause and cardiovascular disease mortality among US adults with hypertension: the NHANES linked mortality study. J Hypertens 2012; 30:284-289.

5 Alvarez-Rodriguez L, Lopez-Hoyos M, Garcia-Unzueta M, Amado JA, Cachon PM, Martinez-Taboata VM, et al. Age and low levels of circulating vitamin $D$ are associated with impaired innate immune function. J Leukoc Biol 2012; 91:829-838.
6 Ruiz-Irastorza G, Egurbide MV, Olivares N, Martinez-Berriotxoa A, Aguirre $\mathrm{C}$, et al. Vitamin $\mathrm{D}$ deficiency in systemic lupus erythematosus: prevalence, predictors and clinical consequences. Rheumatology (Oxford) 2008; 47:920-923.

7 Tan EM, Cohen AS, Fries JF, Masi AT, McShane DJ, Rothfield NF, Shaller JG, et al. The 1982 revised criteria for the classification of systemic lupus erythematosus. Arthritis Rheum 1982; 25:1271-1277.

8 Bombardier C, Gladman DD, Urowitz MB, Caron D, Chang $\mathrm{CH}$. Derivation of the SLEDAI. A disease activity index for lupus patients. The committee on prognosis studies in SLE. Arthritis Rheum 1992; 35:630-640.

9 Wielders JP, Wijnberg FA. Preanalytical stability of 25(OH)-vitamin D3 in human blood or serum at room temperature: solid as a rock. Clin Chem 2009; 55:1584-1585.

10 Fragoso TS, Dantas AT, Marques CD, Rocha Junior LF, Melo JH, Costa AJ, Duarte AL, et al. 25-Hydroxyivitamin D3 levels in patients with systemic lupus erythematosus and its association with clinical parameters and laboratory tests. Rev Bras Reumatol 2012; 52:60-65.

11 Toloza SMA, Cole DE, Gladman DD, Ibanez D, Urowitz MB, et al. Vitamin D insufficiency in a large female SLE cohort. Lupus 2010; 19:13-19.

12 Nagpal S, Na S, Rathnachalam R. Noncalcemic actions of vitamin D receptor ligands. Endocr Rev 2005; 26:662-687.

13 Kamen DL, Aranow C. The link between vitamin D deficiency and systemic lupus erythematosus. Curr Rheumatol Rep 2008; 10:273-280.

14 Damanhouri LH. Vitamin D deficiency in Saudi patients with systemic lupus erythematosus. Saudi Med J 2009; 30:1291-1295.

15 Handono K, Daramatasia W, Pratiwi D, Sunarti S, Wahono S, Handono $\mathrm{K}$, et al. Low level of vitamin $\mathrm{D}$ increased dendritic cell maturation and expression of interferon- $\gamma$ and interleukin-4 in systemic lupus erythematosus. J Pharm Biol Sci 2012; 2:37-43.

16 Kamen DL, Cooper GS, Bouali H, Shaftman SR, Hollis BW, Gilkeson GS, et al. Vitamin D deficiency in systemic lupus erythematosus. Autoimmun Rev 2006; 5:114-117.

17 Thudi A, Yin S, Wandstrat AE, Li QZ, Olsen NJ, et al. Vitamin D levels and disease status in Texas patients with systemic lupus erythematosus. Am J Med Sci 2008; 335:99-104.

18 Stockton KA, Kandiah DA, Paratz JD, Stockton KA, Kandiah DA, Paratz $\mathrm{JD}$, Bennell $\mathrm{KL}$, et al. Fatigue, muscle strength and vitamin $\mathrm{D}$ status in women with systemic lupus erythematosus compared with healthy controls. Lupus 2012; 21:271-278.

19 Borba VZC, Vieira JGH, Kasamatsu T, Radominski SC, Sato El, LazaretteCastro M, et al. Vitamin D deficiency in patients with active systemic lupus erythematosus. Osteoporos Int 2009; 20:427-433.

20 Amital H, Szekanecz Z, Szücs G, Danko K, Nagy E, Csepany T, et al. Serum concentrations of $25-\mathrm{OH}$ vitamin $\mathrm{D}$ in patients with systemic lupus erythematosus (SLE) are inversely related to disease activity: is it time to routinely supplement patients with SLE with vitamin D? Ann Rheum Dis 2010; 69:1155-1157.

21 Mok CC, Birmingham DJ, Ho LY, Hebert LA, Song $\mathrm{H}$, Rovin $\mathrm{BH}$, et al. Vitamin $D$ deficiency as marker for disease activity and damage in systemic lupus erythematosus: a comparison with anti-dsDNA and antiC1q. Lupus 2012; 21:36-42.

22 Ben-Zvi I, Aranow C, Mackay M, Stanevsky A, Kamen DL, Martinescu $\mathrm{LM}$, et al. The impact of vitamin $\mathrm{D}$ on dendritic cell function in patients with systemic lupus erythematosus. PLoS One 2010; 5:9193. 